\title{
DIFERENÇA E IGUALDADE NAS RELAÇÕES DE GÊNERO NO ESPORTE
}

\author{
F. S. $\operatorname{COSTA}^{1{ }^{1 *}, \text { A. M. SANTOS }}{ }^{2}$ \\ 1,2 Pontifícia Universidade Católica do Rio Grande do Sul - PUCRS / Escola de Humanidades \\ fabiosoares.com@hotmail.com *
}

Submetido 08/08/2018 - Aceito 22/10/2018

DOI: $10.15628 /$ holos.2018.7607

\section{RESUMO}

Esta é uma pesquisa bibliográfica de cunho teórico analítico que tem como objetivo principal discutir as concepções de igualdade e diferença de gênero defendidas por Joan Wallach Scott e relaciona-las ao universo do esporte. Pretendeu-se ancorar as relações de gênero apresentadas pela historiadora estadunidense e relaciona-las às problemáticas observadas no campo esportivo, principalmente, quanto às relações de igualdade e diferença denunciadas e defendidas neste início de século XXI. Ao tratar da história das mulheres a partir de uma perspectiva de gênero, percebe-se que os campos político, social e cultural estão sempre em cena, e por que não inserirmos a questão do esporte no debate? Neste texto observa-se que a reivindicação paradigmática da igualdade, por vezes, em sua própria defesa, paradoxalmente deve ser ressignificada para a diferença.

PALAVRAS-CHAVE: Diferença, Esporte, Gênero, Igualdade.

\section{DIFFERENCE AND EQUALITY IN GENDER RELATIONS IN SPORT}

\begin{abstract}
This is a research bibliographic of analytical theoretical nature that aims to discuss the concepts of equality and gender difference advocated by Joan Wallach Scott and relates them to the world of sport research. It was intended to anchor gender relations presented by American historian and relates them to the problems observed in the sports field, especially in relations of equality and difference denounced and defended at the
\end{abstract}

beginning of XXI century. When dealing with the history of women from a gender perspective, one realizes that the political, social and cultural fields are always on the scene, and why not inserting the issue of sport in the debate? In this paper it is observed that the paradigmatic claim of equality, sometimes in his own defense, paradoxically must be new significance for the difference. 


\section{INTRODUÇÃO À QUESTÃO DO GÊNERO}

As discussões sobre as questões de gênero na academia, nas ruas, bibliotecas, jornais e demais locais de exposição de ideias, são fortuitas, sobretudo, sob o ponto de vista epistemológico, pois contribuem para a produção social, simbólica, material, intelectual e de memória das relações entre as pessoas. Construímos e somos construídos por uma grande diversidade de gêneros inter-relacionais, assim, somos indivíduos que nos relacionamos politicamente, socialmente, culturalmente e esportivamente, pois o esporte é uma construção simbólica moderna, advinda da permuta civilizatória das guerras, ou seja, observando Norbert Elias, os homens, na busca de uma atitude mais civilizatória, passaram a praticar esportes em detrimento do caráter guerreiro.

As relações entre esporte e gênero aqui postas em debate, surgiram como problemática para este estudo, a partir de uma visão curiosa, simplista e incompleta do pesquisador, mas que participou ativamente da construção do presente objeto de estudo. Ela é: Porque as reivindicações por igualdade, observadas, superficialmente, sobretudo nos movimentos feministas desde o fim do século XIX, até os dias atuais, não priorizam como pauta a segregação das mulheres no esporte? Assim, tentar-se-á encontrar nas defesas teóricas de Joan Scott possíveis relações com este contexto instigante de discussão.

Esta é uma pesquisa exploratória de levantamento bibliográfico que tensiona uma corrente teórica defendida por Joan Wallach Scott e apoiada no Brasil por Silvana Vilodre Goellner com dados empíricos de estudo de caso realizado em 2014. É descritiva ao tempo em que relaciona formas e comportamentos em desenvolvimento neste início de século no campo esportivo, apontando perspectivas de um novo olhar sobre as binaridades e hierarquias ainda em prevalência nos esportes.

\section{RELAÇÕES HISTÓRICAS ENTRE GÊNERO E ESPORTE}

Como nosso objeto de análise são questões de gênero e suas imbricações com o esporte, trazemos algumas oportunas contribuições de Judith Butler (2000) sobre a diferença dos sexos, defendendo que a categoria do sexo é, desde o início, normativa: ela é aquilo que Michael Foucault chamou de ideal regulatório. Segundo a autora, é nesse ponto que, ao perceber que o sexo é materializado como prática regulatória que gerencia, produz e transforma os corpos, a autora também nota que existem sinais de que a materialização não é nunca totalmente completa, e que os corpos não se conformam, nunca, completamente, às normas pelas quais sua materialização é imposta. Assim, essa instabilidade transforma-se em possibilidades de rematerialização, abertas por esse processo, que marca um domínio no qual a força da lei regulatória pode se voltar contra ela mesma para gerar rearticulações que colocam em questão a força hegemônica daquela mesma lei regulatória.

É oportuna a interseção de Torrão Filho (2004) sobre as proposições de Joan Walach Scott ao corroborar esse autor, afirmando que o termo gênero surgiu como combate ao determinismo biológico nas relações entre os sexos, acrescentando discussões sociais demasiado importantes, bem como potencializando o termo como discussão e categoria de análise nas pesquisas sociais. 
Citando Scott (1992), três posicionamentos teóricos sobre gênero são historicamente importantes. A tentativa feminista de entender as origens do patriarcado é primeiro posicionamento. Foi seguido pela tradição marxista que busca um compromisso com a crítica feminista; e por último temos a defesa do pós-estruturalismo francês e das teorias de relação do objeto, que buscou na psicanálise a explicação para a produção e a reprodução da identidade de gênero do sujeito. Todavia, o mais importante para nossa discussão passa pela "necessidade de se entender o gênero enquanto a relação entre os sexos, de como é assegurado um significado para os conceitos de homem e mulher e as práticas pelas quais os significados da diferença sexual são definidos." (Torrão Filho, 2004, p.138).

A importância desse discernimento em nosso estudo dá-se porque a concepção de gênero que defendemos é aquela que procura ressignificar/reposicionar as distinções entre os sexos, remodelando conceitos biologicamente postos (macho e fêmea) em homens e mulheres como seres sociais, que têm suas desigualdades marcadas por fatores sociais e não por conta de sua origem biológica. Todavia, fatores socioculturais ainda se encontram incrustados em nossa sociedade e demandam de um percurso temporal de lutas e mudanças ainda por vir, sem prospecção infalível. Vemos esse contexto no que diz Torrão Filho (2004):

Mas a diferenciação entre os sexos pressupõe a definição do que são as características que formam a identidade do masculino e do feminino. Não apenas as mulheres aprendem a ser femininas e submissas, e são controladas nisto, mas também os homens são vigiados na manutenção de sua masculinidade. [...] Este discurso não só cria uma essência do que é ser homem e mulher, uma identidade à qual mulheres e homens não são convidados a interferir, mas mantém intactos todos os preconceitos que diz eliminar. Assim, mulheres não devem ser homens porque elas não têm capacidade para isso, porque isso vai contra sua natureza, como dizia Sêneca, uma mulher que se faz passar por homem é um 'mundo às avessas'. E o homem não deve se rebaixar à condição de uma mulher, por isso ele não deve se preocupar em chorar ou demonstrar seus afetos, pois isto faz parte de seu lado feminino que pode ser expresso, porque é apenas um lado, não uma totalidade, e porque não coloca em risco sua heterossexualidade. (p. 139).

Tal pensamento parece representar boa parte da bibliografia de referência sobre a questão do gênero, e nos reforça as prerrogativas abordadas quando do trato sobre a sua relação com o esporte. Tratamos aqui do que diz a psicóloga social Lígia Amâncio quando trata de gênero, suas representações e identidades:

A configuração das representações, socialmente partilhadas e difundidas, do masculino e feminino é marcada por uma assimetria que se revela na dominância simbólica do masculino, objetivação do ser homem, mas também do ser indivíduo, em relação ao feminino, que define exclusivamente o ser mulher. Mesmo reconhecendo o papel do sexo biológico enquanto fator estruturante destas concepções, a sua organização sócio cognitiva só integra a natureza no feminino, reservando, assim para as mulheres, uma permanente marca de diferença, enquanto que a dominância simbólica do masculino se traduz ainda na extensão dos seus significados para além do grupo concreto dos homens. Ao conferir autonomia analítica à especificidade do feminino, como fizeram algumas correntes da psicologia e da sociologia feministas, corre-se o risco de se confundir a aparência com a realidade reproduzindo, no plano científico, a materialização 
do ser mulher (e do ser homem) que existe ao nível do senso comum e que integra estes seres nos indivíduos dos respectivos sexos, deslocando-os da sua origem social. Embora se possa conceber que, pelo facto do sexo biológico impor às mulheres uma forte marca de diferença, elas tomem mais facilmente consciência de sua condição social do que os homens, cuja identidade coletiva se confunde com a individualidade, não podemos esquecer a formação das representações sociais também se ancora na naturalização dos modos de ser. (Amâncio, 1993, p. 138).

O ancoradouro que se escolheu para o amparo historiográfico das relações entre gênero e esporte nesta pesquisa foi o conjunto de observações de Goellner (2012) na sua recente produção Gênero e esporte na historiografia brasileira: balanços e potencialidades. Neste texto, a autora credita à década de 1970 como o berçário das discussões sobre gênero na história dos esportes, sobretudo na Europa (principalmente a francesa) e Estados Unidos da América, dez anos antes do início das discussões em nosso país, e que recebeu importantes contribuições das pesquisas acadêmicas, do movimento feminista (décadas de 1960 e 1970) e seu combate à negligência da experiência feminista, tentando produzir visibilidades sobre as mulheres. Neste espaço temporal, Goellner (2012) destaca a importante contribuição do ensaio de Joan Scott, Gender: a useful category of historical analysis, que propõe a categoria de gênero como uma ferramenta analítica, ou seja, inaugurando a mudança analítica referencial de pesquisa, centrada nas mulheres, para um novo referencial: o caráter relacional entre os sexos, pois existe uma oposição clara entre as conotações sociais do gênero em relação às do sexo.

Quanto à relação entre gênero e esporte, Goellner (2012) destaca dois estudos importantes: 1) o esporte é sexuado, pois é praticado por ambos os sexos (Hargreaves, 1986) e 2) é generificado, pois são expressas e construídas identidades masculinas e femininas (Silva, 2007), que inicial a produção de espaços de discussão sobre masculinidades e feminilidades, quebrando as amarras da naturalização dos corpos e da aceitação de que a biologia dos corpos amparam as diferentes experiências esportivas vividas por homens e mulheres.

Goellner (2012) denuncia uma dupla marginalidade histórica nesta relação entre esporte e gênero. A primeira diz respeito à pequena atenção dada pelos feminismos às discussões sobre o tema, e a segunda refere-se ao fato dos estudos historiográficos do esporte ignorarem a própria generificação que o estrutura, apoiando-se novamente para esta assertiva em Silva (2007). Todavia, na contramão desta marginalidade, a autora destaca alguns pontos essenciais para as discussões deste tema aqui proposto:

Em que pese essa dupla marginalidade, é necessário ressaltar que vários objetos atualmente investigados no campo da história do esporte foram possíveis apenas em função da contribuição advinda dos feminismos e de suas proposições políticas e acadêmicas. Ao desconstruírem a representação naturalizada de que homens e mulheres formam-se masculinos e femininos devido às diferenças corporais, sendo que as mesmas justificam determinadas desigualdades, atribuem funções sociais e determinam papéis a serem desempenhados por um ou outro sexo, os estudos feministas e de gênero possibilitaram outros pontos de vista sobre o esporte. Permitiram, por exemplo, identificar que os corpos, as gestualidades, as representações de saúde, beleza e desempenho são construções históricas, as quais, em diferentes tempos e culturas, foram associadas aos 
homens e/ou às mulheres. Tornaram visíveis os processos generificadores constituintes do esporte, ao ressaltarem que são produzidos e reproduzidos nele masculinidades e feminilidades e que estas são sempre históricas, mutantes e provisórias. (Goellner, 2012, p. 48).

Goellner (2007) já evidenciava, nesta década, a contribuição das epistemologias feministas e dos estudos de gêneros para as pesquisas historiográficas sobre mulheres e esportes, e nestas evidencia a importância da inserção, permanência e ampliação da participação das mulheres no campo das práticas corporais e esportivas, inclusive ampliando o olhar para a necessidade de superação da categoria universal "mulher", defendendo a ideia de muitas feminilidades.

Como prólogo desse estudo, a defesa de Goellner (2007) é fundamento basal para nossa pesquisa. Enquanto componente essencial da discussão, o corpo não estar relacionado somente ao esporte e ficar à margem da cultura e da história. O corpo é uma categoria essencial para as pesquisas sociais sobre esporte, pois é construído discursivamente pela sociedade e que hoje deve ser discutido de forma a descentrar o paradigma da naturalização e da binaridade sexual entre os corpos. E daí, corroboramos com a autora na seguinte reflexão:

[...] mais do que buscar explicações que possam medir, comparar ou explicar fisiologicamente as diferenças entre as performances do homem e da mulher no esporte, deveríamos nos indagar porque essas diferenças, e não outras quaisquer, são tomadas como as mais importantes para demarcar tal distinção. [...] Ao invés de afirmar, por exemplo, que mulheres bóiam mais facilmente que homens, deveríamos averiguar os motivos pelos quais a anatomia sexual tem sido território privilegiado para questionar a presença de mulheres em esportes como o futebol, o rugby, as lutas ou o fisiculturismo. (Goellner, 2007, p. 189).

Para esta reflexão, evidenciamos um trabalho de conclusão de curso de graduação em educação física, da Universidade Federal do Piauí, defendido no ano de 2014, pela aluna Lucilene Batista Melo, que traz os resultados de uma investigação sobre o olhar de treinadores e praticantes de artes marciais sobre a prática dos esportes de lutas por mulheres. E nele, ainda observamos um olhar binarizado e preconceituoso, apresenta uma defesa da igualdade entre os sexos, mas que carreia resíduos fortes de um patriarcalismo que ainda é muito forte nos esportes de lutas. (Melo, 2014)

Na pesquisa exploratória realizada observou-se a existência modal de duas correntes de considerações nos estudos sobre gênero e esporte. A primeira continua reafirmando a categorização identitária de homem e mulher, negando a multiplicidade de diferenças existentes em cada uma dessas categorias. É adepta dos conceitos esteriotipais de masculinidade e feminilidade, e que atribui características distintas de biologia, comportamento e funções sociais. Essa corrente destaca-se negativamente pela pouca ou quase nenhuma problematização sobre a inserção, adesão e permanência de homens e mulheres no universo cultural do esporte, e tem como a habilidade "força" uma das suas principais bases de argumentação e diferenciação entre homem e mulher.

A segunda, na sua contramão, ou seja, uma corrente que potencializa ao extremo as divergências inerentes a cada uma dessas categorias, tornando-as impossíveis de se generalizar. Essa corrente acredita que marcadores sociais (raça, geração, sexo, religião e classe social) 
provocam distinções entre homens e mulheres, aceitando a diversidade dos modos de ser de um e de outro polo dessa relação.

Destarte, pensamos outra via a considerar. E nesta, utilizamos os apontamentos de Joan Wallach Scott para auxiliar-nos na apresentação desta nova possibilidade, que faz necessária uma reflexão atenta para os conceitos de igualdade e diferença e de como estes podem agir positiva ou negativamente nas abordagens sobre esporte, gênero e mulher.

\section{GÊNERO, ESPORTE E O ENIGMA DA IGUALDADE}

Em seu texto $O$ enigma da igualdade, Scott (2005) desnuda a base fundante das discussões sobre gênero desde a década de 1990 ao ano de 2005 e apresenta uma nova forma de enxergar as questões de gênero. De fato, percebe-se que a motivação da autora para justificar o estudo foi a de que comumente relacionamos os conceitos de igualdade e diferença, indivíduo e grupo, como antagônicos e excludentes, contudo, não é desta forma que a historiadora estaduniense os vê. Scott (2005) os vê interconectados, tensos e inter-relacionados, devendo ser tomados em termo de paradoxo e não de oposição. Eis aqui a justificativa para o título de nosso estudo.

Crê-se que o hábito por optar por uma ou outra coisa é um dos habitus (Bourdieu, 2003) há que muito tempo nos acostumamos, trazendo dificuldades para a compreensão da postura tomada pela autora tanto quanto a igualdade e diferença como quanto aos conceitos de identidade coletiva e identidade individual. Desta forma, acredita-se que nas relações de gênero no campo esportivo (Bourdieu, 2003) não seja diferente: esportes para homens e esportes para mulheres.

Aprende-se com Scott (2005) que, paradoxalmente a identidade individual é construída apoiando-se na identidade coletiva (de grupo), mas contra ela também, pois se observa que a própria denúncia da situação das "minorias" - feitas minorias por processos históricos de diferenciação social - evidencie as discriminações sofridas, o faz exatamente para combater estas mesmas discriminações.

O texto de Scott (2005) esclarece que há uma dissimulação na abstração do conceito de indivíduo, que quer parecer único e individual, mas é normativo e atribuído socialmente. E exemplifica oportunamente a questão: raça é questão de negritude e não de branquitude; gênero é uma questão de mulher e não de homem. Assim, a autora procura alertar o leitor para os processos de diferenciação social construídos discursivamente, e que se aproximam de uma falácia que conserva e mantém as instituições sociais que asseguram essas diferenciações.

Nesta produção Scott (2005) cita uma outra produção sua: A cidadã paradoxal: as feministas francesas e os direitos do homem e parte de biografias de quatro sufragistas francesas (Olympe de Gouges, Jeanne Deroin, Hubertine Auclert e Madeleine Pelletier) para discutir a história do feminismo, bem como os dilemas do feminismo contemporâneo. Ela rejeita uma perspectiva linear e contínua da história e pensa que os conflitos recorrentes do feminismo devem ser vistos como sintomas das contradições nos discursos políticos que produziram o próprio feminismo; em outras palavras, o feminismo nasce a partir das ideias do individualismo, dos direitos e das obrigações sociais do indivíduo e, ao mesmo tempo, critica esse mesmo corpus de ideias ao questionar a pretensa universalidade da noção de indivíduo que excluía as mulheres. 
O paradoxo entre igualdade e diferença, identidade individual e coletiva, pode ser percebido na obra de Joan Scott quando a autora acredita que a) a igualdade é um princípio absoluto e uma prática historicamente contingente; $b$ ) as identidades de grupo definem indivíduos e renegam a expressão ou percepção plena de sua individualidade; c) as reivindicações de igualdade envolvem a aceitação e a rejeição da igualdade de grupo atribuída pela discriminação, ou seja, os termos de exclusão sobre os quais essa discriminação está amparada são ao mesmo tempo negados e reproduzidos nas demandas pela inclusão; e d) não é a ausência ou a eliminação da diferença, mas sim o reconhecimento da diferença e a decisão de ignorá-la ou de levá-la em consideração. Assim, a igualdade está na decisão em minimizar as diferenças ou mesmo em ignorar sua existência. Já a diferença apresenta-se como uma forma de organização social. E sobre ela é que Scott (2005) defende seus posicionamentos mais importantes. Para ela, percebe-se que o indivíduo possui igualdades perante a lei, contudo, socialmente são diferentes. Assim, esclarece: "sua desigualdade repousa em diferenças presumidas entre eles, diferenças que não são singularmente individualizadas, mas tomadas como sendo categóricas. A identidade de grupo é o resultado dessas distinções categóricas atribuídas" (p. 23). Desta forma, é possível entender o porquê de que a pertença a um determinado grupo dificulta a igualdade dos indivíduos perante a lei. Aí repousa a problemática do conceito abstrato entre a individualidade e a universalidade, bem como uma das suas mais severas críticas localizadas na análise: "a política tem sido descrita como a arte do possível; eu preferiria chamá-la de negociação do impossível..." (p. 29).

\section{POR UMA RELAÇÃO PARADOXAL ENTRE GÊNERO E ESPORTE}

Ao retomar Goellner (2012), percebemos que os estudos que tratam de gênero e esportes pouco se relacionam com as bases teóricas feministas, contudo, a categoria "gênero" é tributária destas bases. Assim, o reconhecimento de seu valor epistemológico é necessário. Contudo, o que pretendemos com este estudo é tensionar esta relação, e isto pode ser iniciado a partir do assertiva de que nas últimas décadas os discursos que narram o esporte como campo eminentemente masculino vem sofrendo cisões, a emergência e legitimação de um novo paradigma que envolve a discussão sobre gênero, mesmo que timidamente, vem acontecendo. Neste contexto, os processos "generificados" e "generificadores" (p. 52) que estruturam as relações nos esportes devem ser considerados justamente por terem em sua concepção epistemológica a crença que todos os espaços, inclusive os esportivos, são espaços de generificação.

Fuller (2006) esclarece que fatores como a competitividade e o rendimento representam os valores culturais do esporte e que este é ordenado e regulado por tradições e tabus, sobretudo, relacionados às questões de gênero. Contudo, reconhece que o esporte é uma instituição social generificada, que exclui, distingue status e poder, principalmente em relação às minorias, que ainda são as mulheres e os transgêneros. A autora utiliza o conceito de hegemonia de Gramsci para fundamentar a dominação masculina no planisfério global e nos esportes, legitimada pela "maculine-powered society", reforçando sua defesa principal, a de que o esporte, enquanto fenômeno cultural é perpassado por discursos e atravessado pelo complexo campo dos gêneros e da linguagem. 
Outra contribuição importante para esta discussão é a desenvolvida por Knijnik (2010) que propõe trazer o debate sobre gênero para o real campo das práticas corporais e esportivas. As masculinidades e as feminilidades são destaque em sua produção que nos ajuda a compreender que atualmente, não apenas a mulher e o feminino estão excluídos do "jogo", mas também de outros atores sociais, aqueles que não se adequam às formas corporais padronizadas e estipuladas pelos valores androcêntricos esportivos.

É inegável a existência de um consenso por parte da comunidade científica que aborda as questões de gênero (Devide et al. 2011) de que há uma interpretação do desporto como uma área de reserva masculina, onde as mulheres tendem a sofrer questionamentos em relação às identidades de gênero e sexual, além de sofrerem com o estereótipo da masculinização. Contudo, como nos ensina Scott (2005), o gênero deve ser assumido como categoria de análise e, a partir disso, deve ser pensado como relevante nas diferentes esferas institucionais sociais, e nestas inserimos o esporte.

Todo esse contexto de normalização no esporte vem sendo bastante discutido na academia de maneira critica há bastante tempo, todavia, não tão eloquentemente quanto na última década. Neste itinerário, diversos estudos têm desenvolvido reflexões sobre esta questão nos últimos dois anos, dos quais destacamos o de Camargo \& Kessler (2017), o dossiê temático da Revista Estudos Feministas (volume 26, n.1, janeiro a abril de 2018 - Universidade Federal de Santa Catarina), o livro de Fabiano Pires Devide - Estudos de gênero na educação física e no esporte (2017) e o estudo de Bettine, M., Gutierrez, D. M. \& Oliveira, A. (2017), com a análise sobre corpo e feminilidade de jogadoras brasileiras de rugby.

Camargo \& Kessler (2017) questionam esta normatividade instituída no meio esportivo, inclusive discutindo os conceitos de masculinidade e feminilidade como ficções políticas vigentes nas arenas esportivas e objetos de validação de visibilidade para a mídia mainstream (TV, internet, jornais e rádios voltados para o grande público e com acesso gratuito), pois o que não se enquadra nas modalizações de normalidade tem sua visibilidade midiática marginalizada. Os autores trazem uma problemática pertinente que é a da construção de um mundo esportivo (masculinizado) que não exerce a alteridade quando se trata de não-masculinos. Essa prática se materializa com a marginalização do diferentes e com a construção de subcategorias (inferiorizadas sob todos os aspectos) competitivas, pretensamente incluídas, mas que, na verdade, são eficazmente deslegitimadas.

Apesar da pujante força deste modelo esportivizado de dominação fálica, os autores apresentam inúmeras facetas de resistências por mulheres, pessoas com deficiências, transgêneros, bissexuais, gays e lésbicas no mundo esportivo que nos ajudam a compreender que a permissão para o trânsito dessas "dissonâncias" no meio esportivo é exercida com força e autoridade pelas mídias, técnicos, médicos, fisioterapeutas, preparadores físicos, proprietários dos clubes, enfim, um conglomerado macro e micro de dominância masculina que impede esse necessário exercício de autoridade. E ainda, para os autores, é preciso ir além do binômio sexual e do protagonismo de bio-mulheres campeãs esportivas, é preciso dar eloquência aos tantos corpos desgenerificados que são apresentados em diversas modalidades esportivas, corpos que não tem identificação ao significado que é dado a eles por essa visibilidade modal que também apresenta 
os corpos polarizados não somente pela biologia, mas com a identificação do super corpo, masculino, e do corpo erótico, feminino. Outros corpos têm que se fazer valer.

Todo esse sistema de controle exercido no mundo esportivo em torno da normalidade é evidenciado e tensionado também nas reflexões de Camargo (2018). O autor pensa a realidade homossexual dentro de um marco de referências heteronormativo e conclui que tornar público (sair do armário) sua sexualidade nos entremeios discursivos de jogos esportivos coloca em xeque toda essa condição de masculinidade hegemônica. Com ele entendemos que o esporte funciona com um poderoso executor de controle, um demarcador de gêneros, forte e fraco, um potente regulador de poder, inclusive de alguns modelos de corpos sobre outros.

Os corpos apresentam uma miríade de possibilidades performativas, entretanto, os importantes e diversos estudos apresentados na obra de Devide (2017) esclarecem que a busca pela equidade de condições de competição, visibilidade e exercício de alteridade nas relações entre tantos, ainda é um caminho longo a ser percorrido, contudo, já trilhado e em franca aceleração. Todavia, os dados empíricos de diversas pesquisas ainda apontam para a invisibilidade do que não é masculino, desde a aulas de educação física na escola até os veículos midiáticos, de forma potente e eficaz.

A resistência a este contexto é possível, assim como Silva e Nazário (2018) esclarecem ao apresentar o protagonismo de um grupo de mulheres atletas de futsal na construção de uma imagem de empoderamento feminino no esporte. Esta pesquisa esclarece que um grupo de atletas de futsal construiu estratégias de fortalecimento via participação em eventos sociais, vínculos com patrocinadores, criação e manutenção de escolinhas pedagógicas e com a conquista de espaços midiáticos, para problematizar as representações hegemonicamente masculinas no esporte. Foram tensionados atravessamentos de gênero no esporte e esse controle generificado pôde ser colocado em discussão.

Pensa-se assim em tratar das políticas esportivas e considerar a igualdade nestas tendo como norte "a negociação de identidades e dos termos das diferenças entre elas" (Scott, 2005, p.29). Desta forma, defendemos que o gênero deve ser adotado como um forte marcador de diferenças, que precisa de visibilidades e dizibilidades. Os sujeitos no esporte precisam ser visualizados a partir dessa categoria, não permitindo a eliminação da diferença. Assim, a construção da percepção dos sujeitos esportivos a partir do reconhecimento das diferenças é mister, pois o cerne das tensões nessa discussão está em ignorar ou levar em consideração estas diferenças.

\section{CONSIDERAÇÕES FINAIS}

Por todo o contexto apresentado direcionamos nossas considerações finais na necessidade de que, assim como em outras esferas institucionais sociais, no esporte, é preciso libertarmo-nos das amarras do binarismo sexual ainda tão presente em nossa sociedade.

Isto posto, em detrimento de outras manifestações sociais, corporais, de masculinidade e feminilidade que já habitam o meio esportivo, ou seja, outros elementos inauguram outros sujeitos que precisam ser considerados, desestabilizando a tão defendida relação binária nos 
esportes. Aqui externamos, criticamente, a inculcação de termos como hetero/homo, homem/mulher como sujeitos sociais e binários, que esquecem a existência destes mesmos de maneira plural e diferentes, diversos de subjetividade e corporeidade. Pensamos que o respeito à diversidade e a compreensão quanto às diferenças são a pauta que urge nas discussões de gênero e de sua relação com os esportes, pois o diferente precisa ser aceito socialmente, que mesmo na faceta social esportiva, cheia de normatizações, regramentos e limites, precisa ser considerado.

É o paradoxo da igualdade e das diferenças a que Joan Scott (2005) argumenta e defende. Pena que no campo esportivo a primariedade das relações de gênero ainda imperam, que o conservadorismo e o binarismo fisiológico sejam as pontas das lanças nas discussões sobre suas formatações, pois a competitividade e a exclusão são objetos das tentativas de perpetuação da binaridade fisiológica esportiva e do empoderamento masculino esportivizado.

\section{REFERÊNCIAS}

Amâncio, L. (1993). Gênero: representações e identidades. Sociologia - Problemas e Práticas, 14, 127-140.

Butler, J. (2000). Corpos que pesam: sobre os limites discursivos do "sexo". In G. L. Louro (Org.), $O$ corpo educado: Pedagogia da sexualidade (2. ed., pp 110-127). Belo Horizonte: Autêntica.

Bettine, M., Gutierrez, D. M. \& Oliveira, A. (2017, Setembro/Dezembro). Corpo e feminilidade a partir da experiência das jogadoras de rugby brasileiras. Revista Brasileira de Estudos do Lazer, 4 (3), 139-153.

Bourdieu, P. (2003). A dominação masculina. Rio de Janeiro, RJ: Editora Bertrand Brasil.

Camargo, W. X. (2018). O armário da sexualidade no mundo esportivo. Estudos Feministas, 26(1), 1-18. Retrieved from http://www.jstor.org/stable/90018808.

Camargo, W. X., Kessler, C. S. (2017, Janeiro/Abril). Além do masculino/feminino: gênero, sexualidade, tecnologia e performance no esporte sob perspectiva crítica. Horizontes Antropológicos, 47 (23), 191-225.

Devide, F. P. (2017, Org.). Estudos de gênero na educação física e no esporte. Curitiba, PR: Appris.

Devide, F. P., Osborne, R., Silva, E. R., Ferreira, R. C., Clair, E. S. \& Nery, L. C. P. (2011, Janeiro/Março). Estudos de gênero na educação física brasileira. Motriz, 17 (1), 93-103.

Elias, N. (1994). O processo civilizador: uma história dos costumes - v. I (2a ed.) Rio de Janeiro, RJ: Jorge Zahar.

Fuller, L. K. (2006, Org.). Sport, rhetoric, and gender: Historical perspectives and media representations. New York: Palgrave MacMillan.

Goellner, S. V. (2012). Gênero e esporte na historiografia brasileira: balanços e potencialidades. Revista Tempo, 19(34), 45-52.

. (2007, Maio/Agosto). Feminismos, mulheres e esportes: questões epistemológicas sobre o fazer historiográfico. Movimento, 13(02), 171-196.

Hargreaves, J. (1986). The Social Production of Gender Through Sport. Theory, Culture and Society, 3(1), 114-119. 
Knijnik, J. D. (2010, Org.). Gênero e Esporte: masculinidades e feminilidades. Rio de Janeiro, RJ: Apicuri Editora.

Melo, L. B. (2014). Representações sociais da mulher praticante de esportes de combate na visão de atletas de artes marciais de Teresina/PI (Trabalho de Conclusão do Curso de Licenciatura Plena em Educação Física). Departamento de Educação Física, UFPI, Teresina.

Silva, A., \& Nazário, P. (2018). Mulheres atletas de futsal: Estratégias de resistência e permanência no esporte. Estudos Feministas, 26(1), 1-15. Retrieved from http://www.jstor.org/stable/ 90018804

Scott, J. W. (2002). A cidadã paradoxal: as feministas francesas e os direitos do homem. (É. A. Funck, Trad.) Florianópólis: Editora Mulheres. . (2005, Janeiro/Abril). O enigma da igualdade. Estudos Feministas, 13(1), 216, 11-30. . (1992). História das mulheres. In: P. Burke. (Org.) A escrita da história: novas perspectivas. (pp. 64-96). São Paulo, SP: Unesp.

Silva, P. (2007) A construção/estruturação do género na educação física. Lisboa, Loures.

Torrão Filho, A. (2005, Janeiro/Junho). Uma questão de gênero: onde o masculino e o feminino se cruzam. Cadernos Pagu, 24, 127-152. 